\title{
BIBLIOTECÁRIO ESCOLAR E FAKE NEWS: EVIDÊNCIAS DA CONTRIBUIÇÃO DA BIBLIOTECA ESCOLAR
}

\author{
SCHOOL LIBRARIAN AND FAKE NEWS: EVIDENCE FROM SCHOOL LIBRARY \\ CONTRIBUTION
}

\author{
Janaína Ferreira Fialho Martha', Suzana Cabral NunesII, Paulo Roberto Fernandes \\ Júnior'II, Giovana Gabrielli Rocha Gois ${ }^{I V}$, Maria Mirella Borges Santana ${ }^{V}$, Raphaela Mota \\ Pereira Veloso ${ }^{V I}$, Wictor Alexandre da Silva Santos ${ }^{V I I}$
}

Recebido em: $28-12-2018$
Aceito em:05-03-2019

\begin{abstract}
Resumo
As fake news ou notícias falsas têm ganhado repercussão internacional e sua disseminação se dá principalmente pelas redes sociais. Este artigo busca compreender o papel do bibliotecário escolar nesse cenário e tem como objetivo geral conscientizar os alunos do ensino médio sobre a circulação e uso das notícias falsas, bem como estruturar uma ação de capacitação para os mesmos. A pesquisa tem abordagem quanti-qualitativa e os instrumentos de coleta de dados utilizados foram um questionário com perguntas fechadas e uma pergunta aberta ao fim da palestra. A palestra para 45 alunos do ensino médio teve participação direta dos discentes do curso de Biblioteconomia e Documentação da Universidade Federal de Sergipe e da bibliotecária do colégio particular. Os principais resultados apontaram que a palestra foi bastante esclarecedora para a turma, em diversos aspectos. Demonstrou também que os alunos do ensino médio frequentam pouco a biblioteca do colégio e que a mesma desenvolve alguns projetos importantes de leitura. Os jovens apontaram diversos métodos de avaliação da informação na internet. Sugere-se que a bibliotecária desenvolva projetos em parceria com os professores sobre a prática da pesquisa e de desenvolvimento do letramento informacional dos alunos da educação básica.
\end{abstract}

Palavras-chave: Bibliotecas escolares. Fake news. Ensino médio. Letramento informacional.

\begin{abstract}
Fake news or fake news has gained international repercussion and its spread is mainly through social networks. This article seeks to understand the role of the school librarian in this scenario and its general objective is to raise the awareness of high school students about the circulation and use of false news, as well as to structure a training action for them. The research has a quanti-qualitative approach and the instruments of data collection used were a questionnaire with closed questions and an open question at the end of the talk. The lecture for 45 high school students had direct participation of the students of the Library and Information Science course of the Federal University of Sergipe and the librarian of the private college. The main results pointed out that the lecture was quite enlightening for the class, in several aspects. He also showed that high school students rarely attend high school libraries and that they develop some important reading projects. The young people pointed out several methods of evaluating information on the internet. It is suggested that the librarian develop projects in partnership
\end{abstract}

\footnotetext{
' Doutora em Ciência da Informação - Professora do Departamento de Ciência da Informação e do Mestrado Profissional em Ciência da Informação da Universidade Federal de Sergipe - e-mail: jajafialho@gmail.com IIDoutora em Ciência da Informação - Professora do Curso de Biblioteconomia e Documentação da UFS - email: marthasuzana@ hotmail.com

III Estudante do curso de Biblioteconomia e Documentação da UFS - e-mail: paulo.r_junior@hotmail.com

IV Estudante do curso de Biblioteconomia e Documentação da UFS - e-mail: giovana_gabi10@ hotmail.com

${ }^{v}$ Estudante do curso de Biblioteconomia e Documentação da UFS - e-mail: mirellaborges.mb26@gmail.com

VI Estudante do curso de Biblioteconomia e Documentação da UFS - e-mail: raphaveloso164@gmail.com

VII Estudante do curso de Biblioteconomia e Documentação da UFS - e-mail: wictoralexandre93@gmail.com
} 
with teachers on the practice of research and development of informational literacy of students in basic education.

Keywords: School library. Fake news. High school. Information literacy.

\section{INTRODUÇÃO}

Um dos temas que mais têm sido discutidos recentemente é a circulação de notícias falsas ${ }^{1}$ em diferentes canais de comunicação, em especial nas redes sociais. No Brasil, o debate ganhou destaque com o projeto de lei 6.812/2017 do deputado Luiz Carlos Hauly (PSDB/PR), que prevê criminalizar a divulgação ou compartilhamento de informação falsa ou incompleta na rede mundial de computadores, levantando as questões sobre o poder das notícias falsas compartilhadas na internet.

Sabe-se que a notícia veiculada nesses canais tem como objetivo transmitir uma informação, a qual pode servir a quem a recebe de diferentes maneiras, em especial contribuindo para elevar a quantidade de informação que essa pessoa tem acesso, e, consequentemente, tornando-a capaz de produzir conhecimento sobre a notícia veiculada, desde que associada a outras fontes de informação. Tal movimento, que ocorre a nível cognitivo, tem potencial para aumentar a reflexão e criticidade, gerando na sociedade cidadãos mais críticos e conscientes do seu papel social, do poder da informação e de sua disseminação e uso.

Porém, o acesso facilitado e o volume exponencial de informação produzida têm gerado uma explosão informacional sem precedentes, o que torna complexa a tarefa de filtrar informações de boa procedência em relação àquelas que são criadas para confundir as pessoas, levando-as a tomar decisões equivocadas. Assim, se questiona: porque as notícias falsas viralizam nas redes sociais? Quais as consequências para a formação de opinião dos alunos do ensino fundamental e médio (crianças e adolescentes), cidadãos em plena formação?

Para além disso, faz-se necessário entender qual o papel do profissional bibliotecário e das bibliotecas na formação do letramento informacional dos alunos, ou seja, em que medida eles contribuem para a formação de cidadãos mais críticos e conscientes com o uso da informação. É sabido que as bibliotecas escolares desenvolvem diversas ações e projetos relativos à busca e uso de informações e que os mesmos têm um impacto sobre o comportamento informacional das crianças e jovens, conforme demonstram as literaturas brasileira e estrangeira.

Dessa forma, surgiu o seguinte problema que direcionou a pesquisa: a biblioteca do colégio particular pesquisado desenvolve projeto(s) que proporcionam um olhar mais crítico nos alunos em relação à busca e ao uso da informação? Se sim, quais? Existe algum projeto relacionado diretamente às notícias falsas? Assim, buscou-se compreender também a importância do profissional bibliotecário nesse contexto. Campello e Abreu (2005, p. 179) sugerem que:

[...] para ser capaz de construir um novo paradigma e de contribuir para a educação de pessoas competentes em informação o próprio bibliotecário deve ser competente em informação e dominar as habilidades necessárias para realizar o processo de pesquisa adequadamente.

Para o melhor resultado das atividades de uma biblioteca escolar, há a necessidade de se trabalhar em cooperação com a escola ou instituição de ensino na qual esteja integrada, e estar disponível para atender aos professores, alunos e demais interessados. Cabe ao

\footnotetext{
${ }^{1}$ fake news: por opção dos autores, adotou-se o termo traduzido.
} 
bibliotecário estar presente para estimular competências de leitura, interpretação de informações, maior senso crítico e criatividade, também estimulando vários aspectos para exercer seu papel cidadão dentro e fora da escola. Tais competências são urgentes no contexto social atual, quando se trata das chamadas notícias falsas, que fogem da realidade e se tornam um poderoso meio de manipulação e com forte potencial de gerar confusão e dúvida na sociedade.

O objetivo geral da pesquisa foi conscientizar os alunos do ensino médio sobre a relevância das notícias falsas no cenário informacional atual, e ainda os objetivos específicos foram: estruturar uma ação de capacitação em relação às notícias falsas por intermédio da biblioteca do colégio; demonstrar para a comunidade escolar em geral a importância do trabalho do bibliotecário em relação ao preparo dos alunos para lidar criticamente com o mundo da informação, e particularmente em relação às notícias falsas.

O colégio pesquisado teve sua fundação iniciada em 1974, no mesmo período em que foi realizado o primeiro pré-vestibular de Aracaju, localizado na rua Maruim. No ano seguinte o colégio já estava funcionando como um convênio do colégio Salesiano, trabalhando com a parte profissionalizante que era exigida por lei naquela época. Em 1976 iniciou suas atividades na sede localizada no centro da cidade de Aracaju, contando com 270 alunos. Em 1981 o colégio atingiu o número de 1000 alunos e nesse mesmo ano teve início a construção da sua atual sede. No entanto, foi no ano de 1987 que a sede no centro foi desativada e o colégio teve seu funcionamento pleno no outro núcleo, contando atualmente com cerca de 1500 alunos.

\section{REFERENCIAL TEÓRICO}

A Federação Internacional de Associações e Instituições Bibliotecárias (IFLA) publicou em 2016 um artigo no qual apresentou oito passos para o reconhecimento de uma informação falsa, apresentados na Figura 1: 1) estudo da fonte (não se concentre apenas na notícia, investigue o site, seu objetivo e a informação de contato); 2) leitura de todo o texto (um título atraente pode querer chamar a atenção, qual é a história completa?); 3) descobrimento do autor (faça uma procura rápida sobre o autor, é confiável?, é real?); 4) busca por fontes adicionais (clique nos links e verifique se há dados que respaldam a informação); 5) verificação da data (notícias antigas podem não ser mais relevantes na atualidade); 6) certificação de que não seja uma brincadeira (se a notícia for muito extravagante, pode ser uma sátira, investigue o site e a autoria); 7) consideração de sua orientação (considere que seus valores podem mudar sua opinião) e 8) busca por uma pessoa com experiência (peça ajuda na biblioteca ou consulte um site de verificação) (KIELY; ROBERTSON, 2016).

Figura 1 - Como identificar notícias falsas

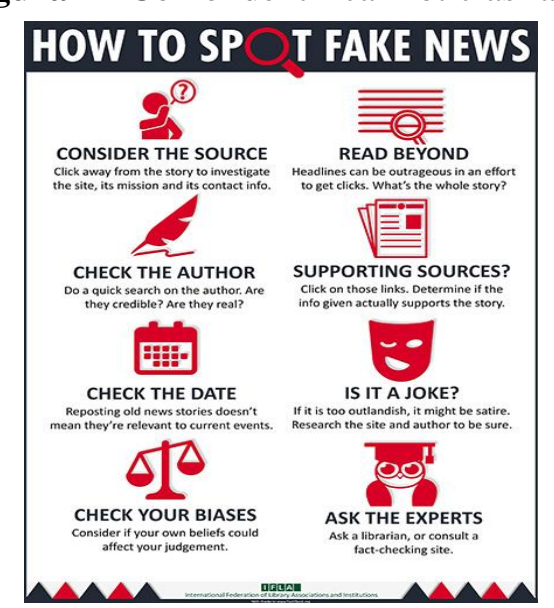

Fonte: https://www.factcheck.org/2016/11/how-to-spot-fake-news/. 
Todas essas medidas apresentadas pela IFLA dão conta do letramento informacional (LI) necessário a todo cidadão. O letramento informacional pode ser conceituado como:

[...] um processo de aprendizagem que favorece o aprender a aprender, visto que engloba conceitos, procedimentos e atitudes que permitem ao indivíduo identificar a necessidade de informação e delimitá-la, buscar e selecionar informação em vários canais e fontes de informação, bem como estruturar e comunicar a informação, considerando os seus aspectos éticos, econômicos e sociais (GASQUE, 2012, p. 46).

Pensando nisso, a Rede de Bibliotecas Escolares de Portugal ${ }^{2}$ apresenta as diferentes literacias ${ }^{3}$ necessárias ao processo de aprendizagem dos alunos: literacia da leitura, literacia das mídias e literacia da informação. Literacias podem ser definidas como "conjunto de conhecimentos, capacidades, atitudes e valores de carácter transversal, indispensáveis a um ensino de qualidade" (REDE, 2017, p. 10). Dessa maneira,

[...] na primeira área, procura associar-se o trabalho das bibliotecas escolares ao desenvolvimento do gosto e das competências de leitura, escrita e comunicação, como condição estruturante da formação pessoal e capacidade de progressão nas aprendizagens. Na segunda área, consideram-se os contributos da biblioteca escolar para o desenvolvimento de competências, propiciadoras de novas formas de aprender, interagir e comunicar através dos média. Na terceira área, associa-se o trabalho da biblioteca ao uso crítico e informado de recursos e ferramentas e a aquisição integrada de conhecimentos associados à literacia da informação (REDE, 2017, p. 16-17).

Esses conceitos de literacia se aproximam muito das diretrizes que um aluno precisa para distinguir uma informação de qualidade de uma notícia falsa. Em especial a literacia das mídias apresenta como o aluno consome as mídias e se expressa de forma ética e responsável para produzir e partilhar informações.

O programa de Portugal busca trabalhar para cada etapa da educação pré-escolar e do ensino básico os conhecimentos/capacidades (denominação utilizada por eles) que deverão ser trabalhados com os alunos para o desenvolvimento do LI, bem como as atitudes/valores importantes para cada ciclo e ainda as estratégias didáticas de operacionalização de tais conhecimentos.

Preocupados com o caos informacional e a velocidade com que as informações circulam na internet, sobretudo nas redes sociais, Leite e Matos (2017, p. 2) discutem o conceito de desinformação e pós-verdade e como está cada dia mais difícil conferir a veracidade das informações, já que:

[...] a correspondência a eventos ou coisas realmente ocorridas, que sempre foi um indicativo mínimo de veracidade, tem se tornado uma qualidade cada vez mais difícil de comprovar, num meio ambiente em que a informação é

\footnotetext{
${ }^{2}$ REDE DE BIBLIOTECAS ESCOLARES. Aprender com a biblioteca escolar. Referencial de aprendizagens associadas ao trabalho das bibliotecas escolares na Educação Pré-escolar e no Ensino Básico. Lisboa: RBE, 2012. 67 p. Disponível em:

〈http://www.rbe.minedu.pt/np4/np4/?newsId=681\&fileName=Aprender_com_a_biblioteca_escolar.pdf $>$. Acesso em: 11. abr. 2018.

${ }^{3}$ Nome dado ao letramento informacional em Portugal.
} 
replicada por diversas fontes, e é cada vez mais difícil para o interagente conferir as fontes originais, sobretudo daquilo que é veiculado pela internet.

Para Aquino (2007), o conceito de desinformação relaciona-se "aos ruídos e redundâncias"; segundo ele, no Brasil a comunicação entre os indivíduos, o mundo e outros sujeitos mostra que eles quase sempre estão submetidos a desinformação ou a pouca informação. Assim, a desinformação somada à prática da pós-verdade transforma os cidadãos em produtores de armadilhas, e distinguir informações verdadeiras de notícias falsas torna-se um grande desafio. Nesse sentido, Corrêa e Custódio (2018, p. 205), afirmam:

\begin{abstract}
À medida em que cada um possui sua própria verdade, baseada não em fatos, mas em crenças pessoais geralmente tendenciosas e carregadas de interesses e julgamentos de valor, a ambiguidade vai ocupando espaços cada vez maiores. Assim, um único fato pode assumir centenas de interpretações diferentes e conflitantes. Começam a ser colocados em xeque os conceitos de honestidade e desonestidade, credibilidade e dúvida, verdade e mentira. Vivese um tempo em que as convicções são mais importantes do que as provas.
\end{abstract}

Sendo assim, muitos fatores implicam na credibilidade da informação. Tendo em vista isto, cabe ao bibliotecário preparar os usuários para que possam selecionar seus meios de comunicação e compará-los com outras fontes, a fim de capacitar e educar seus usuários para terem competências informacionais necessárias para encontrar a informação correta e confiável. Segundo Campello (2003), a educação básica é o momento privilegiado para a formação de usuários de biblioteca.

Neste contexto, a transformação que a informação é capaz de gerar em uma sociedade e a sobrevivência dos bibliotecários em um mundo onde a informação e a desinformação se confundem tornam-se fatos altamente desafiadores. Os bibliotecários devem se conscientizar de seu papel como agentes sociais transformadores no meio educacional. Esses profissionais deverão estar dispostos a sair das estruturas físicas das bibliotecas, flexibilizar seus perfis profissionais e realizar suas tarefas técnicas de maneiras diferentes, analisando seus impactos e ajudando a sociedade a entender as mudanças. Segundo Ortega y Gasset (2006, p. 16):

Para determinar a missão do bibliotecário, é preciso partir não do homem que a exerce, de seus gostos, curiosidades ou conveniências, tampouco de um ideal abstrato que pretendesse definir de uma vez por todas o que é uma biblioteca, mas da necessidade social a que serve vossa profissão. E esta necessidade, como tudo que é propriamente humano, não consiste em uma magnitude fixa, mas é, essencialmente variável, migratória, evolutiva; em suma, histórica.

Ou seja, o bibliotecário deve exercer sua missão em vista das necessidades demandadas da comunidade em que ele atua. No contexto das bibliotecas escolares, Maroto (2012, p. 57) escreve:

As bibliotecas escolares, quando existem, constituem-se geralmente em verdadeiros "depósitos de livros", em mero enfeite da escola, pois se encontram submetidas a um sistema de ensino onde as fontes de informação, na maioria das vezes, são o professor e o livro didático, dificultando e suprimindo assim o trabalho criativo, crítico e consciente, dentro e fora do espaço escolar. 
Essa realidade exposta por Maroto é evidente quando se analisam as condições das bibliotecas escolares brasileiras, diferentemente das diretrizes apresentadas pela Rede de Bibliotecas Escolares de Portugal, as políticas públicas brasileiras mal mencionam o papel efetivo da biblioteca escolar.

Para que a escola possa contar com a participação e o envolvimento da comunidade, especialmente dos familiares dos alunos, nas ações de dinamização e de valorização da biblioteca escolar, faz-se necessário que os professores e bibliotecários desenvolvam um trabalho de sensibilização e de conquista dessa comunidade, trazendo-a para conhecer o espaço, apresentando-lhe os recursos disponíveis e as atividades de promoção da leitura e da pesquisa desenvolvidas ali. Deverão exercer, também, um trabalho de conscientização sobre a importância desse "espaço" e desses recursos para a vida social e cultural dos alunos, professores e dos demais segmentos sociais (MAROTO, 2012, p. 77).

Por fim, vale a pena apontar, por meio de estudos científicos, as evidências positivas da atuação das bibliotecas escolares na aprendizagem dos alunos, particularmente em relação ao uso crítico da informação. O estudo de Ohio realizado em New Jersey nos Estados Unidos com 13.123 alunos da educação básica evidenciou, cientificamente, como a biblioteca faz a diferença no desenvolvimento do LI dos estudantes. (TODD; KUHLTHAU, 2005)

O estudo sugeriu o modelo da biblioteca escolar como agente dinâmico do aprendizado, em três grandes dimensões: informação, transformação e formação (TODD; KUHLTHAU, 2005). No primeiro caso, diz-se respeito à infraestrutura informacional e tecnológica, ou seja, a biblioteca precisa ter bom acervo, alinhado com o currículo da escola; tecnologia para recuperar e disseminar a informação, transformando-a em produtos criativos e literatura de lazer.

Os programas de LI desenvolvidos na biblioteca proporcionam resultados mais elevados de aprendizagem, por meio das orientações fornecidas aos alunos; a biblioteca propicia criação de processos de conhecimento e ensina aos alunos a lidarem com a informação de forma mais crítica, incluindo as atividades de desenvolvimento da leitura e pesquisa, motivando e proporcionando o gosto permanente pela leitura.

No âmbito da formação vislumbra-se os resultados de aprendizado alcançados pelos alunos, eles se tornam mais hábeis para "formular questões, formular um foco para suas pesquisas; explorar, investigar, analisar e sintetizar ideias para criar seus próprios pontos de vista; avaliar soluções e fazer a atividade de reflexão" (FIALHO; GASQUE, 2014, p. 11). Dessa maneira,

A escola não pode mais contentar-se em ser apenas transmissora de conhecimento que, provavelmente, estarão defasadas antes mesmo que o aluno termine sua educação formal; tem de promover oportunidade de aprendizagem que dê ao estudante condições de aprender a aprender, permitindo-lhe educar-se durante a vida inteira. E a biblioteca está presente nesse processo (CAMPELLO, 2016, p. 11).

Campello (2016) reforça o papel da biblioteca escolar nos processos de aprendizagem dos estudantes. Sendo assim, a biblioteca escolar deve trabalhar em conjunto com a direção da escola por meio de projetos e atividades, proporcionando assim o aprendizado contínuo dos alunos. 


\section{METODOLOGIA}

Essa seção é dedicada à forma como a pesquisa foi desenvolvida, visando permitir, através da apresentação dos métodos escolhidos, o auxílio para a compreensão do estudo. A pesquisa bibliográfica foi escolhida por permitir levantar e averiguar o conhecimento das teorias utilizadas neste artigo, a fim de explicar o objeto alvo deste estudo. Sendo, assim, uma base para a sustentação do trabalho realizado, tal pesquisa permitiu que o pesquisador conhecesse o que foi estudado sobre o assunto, sendo consultados livros e artigos científicos sobre a temática.

O estudo tem natureza quanti-qualitativa, o que possibilitou uma interpretação mais ampla dos resultados obtidos pela coleta de dados. Segundo Minayo e Sanches (1993, p. 34):

[...] a relação entre quantitativo e qualitativo, entre objetividade e subjetividade não se reduz a um continuum, ela não pode ser pensada como oposição contraditória. Pelo contrário, é de se desejar que as relações sociais possam ser analisadas [...] e aprofundadas em seus significados mais essenciais. Assim, o estudo quantitativo pode gerar questões para serem aprofundadas qualitativamente, e vice-versa.

Quanto aos objetivos, a pesquisa revelou-se exploratória. A pesquisa exploratória tem "como objetivo proporcionar maior familiaridade com o problema" (GIL, 1991, p. 45); seu problema de pesquisa normalmente está voltado a 'o quê, qual, quais'. Acredita-se ter sido essa uma experiência pioneira no estado de Sergipe, envolvendo bibliotecário e alunos de Biblioteconomia em processo formativo.

A ação implementada proposta foi uma palestra com os alunos do ensino médio sobre notícias falsas, estruturada com os seguintes tópicos: definição, exemplos práticos, reconhecimento de notícias falsas e busca segura na internet, concebida e acompanhada pelos alunos e a professora da disciplina optativa denominada "Organização de Bibliotecas Escolares", do curso de Biblioteconomia e Documentação da Universidade Federal de Sergipe. Todos os alunos participaram da concepção e organização do evento, bem como da análise dos dados coletados por meio do questionário aplicado e também da elaboração do artigo.

A escolha do ensino médio se deu devido à disponibilidade oferecida pelo colégio, ou seja, segundo a compatibilidade com agenda. Antes de iniciar a palestra foram distribuídos os questionários, os quais foram respondidos por 45 alunos do $3^{\circ}$ ano do ensino médio, constituindo a amostra pesquisada, num total de três turmas de ensino médio. Hernández Sampieri, Fernández Collado e Baptista Lucio (2013) salientam que o tamanho da amostra não é critério decisivo na pesquisa qualitativa, mas sim a profundidade na análise para responder aos objetivos propostos. Definem amostra como "um grupo de pessoas, eventos, acontecimentos, comunidades, etc., sobre o qual deveremos coletar os dados" (HERNÁNDEZ SAMPIERI; FERNÁNDEZ COLLADO; BAPTISTA LUCIO, 2013, p. 403).

Os questionários foram respondidos, recolhidos e deu-se início à palestra (Figuras $2 \mathrm{e}$ 3). Após a palestra, bastante interativa com o público, eles responderam à seguinte pergunta aberta: o que essa palestra significou para você? Tal pergunta tinha o objetivo implícito de conhecer o aprendizado significativo sobre a temática. Paralelamente foi criado pelos alunos do curso de Biblioteconomia e Documentação um blog sobre notícias falsas, onde eles poderiam buscar conhecimento sobre o assunto ${ }^{4}$.

\footnotetext{
${ }^{4}$ Disponível em: 〈https://abccontrafakenews.wixsite.com/biblioufs $>$. Acesso em: 31 ago. 2018. 
Figura 2 - Palestra ${ }^{5}$

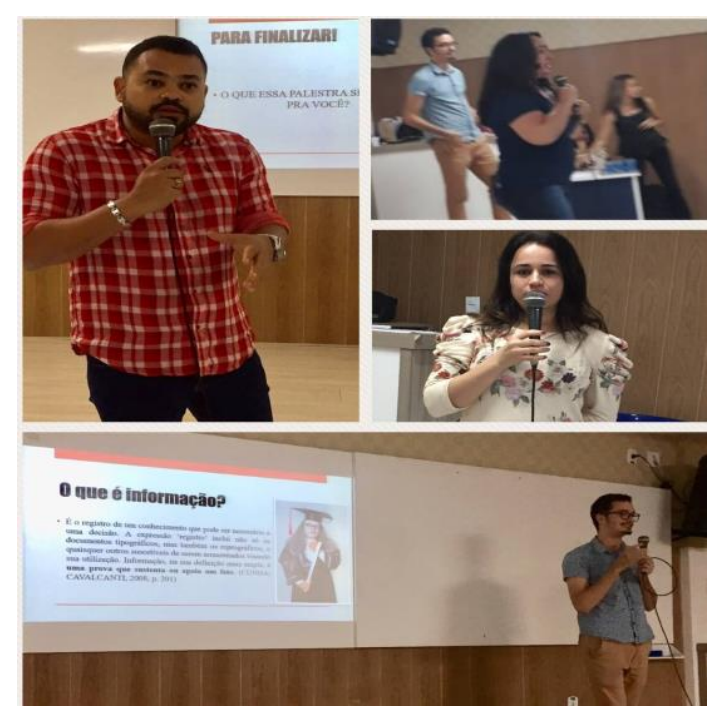

Fonte: arquivo pessoal, 2018.

\section{Figura 3 - Público}

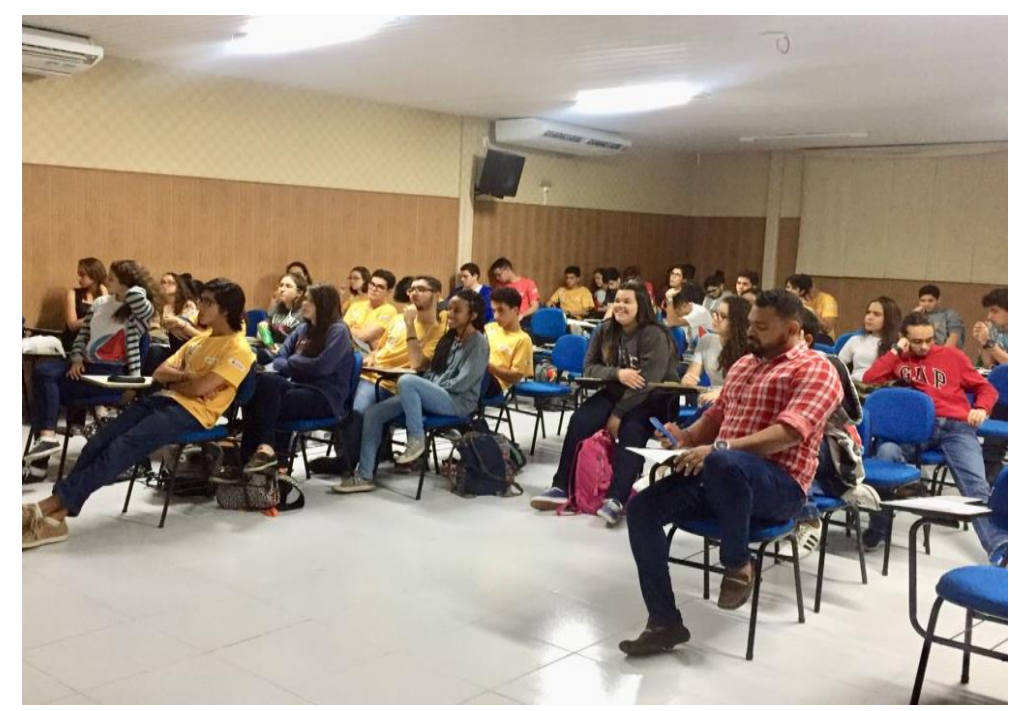

Fonte: arquivo pessoal, 2018.

\section{ANÁLISE E DISCUSSÃO DOS RESULTADOS}

Dentre os respondentes, $47 \%$ eram do gênero feminino e 53\% do masculino. A primeira pergunta era sobre a frequência à biblioteca do colégio, sendo que $64 \%$ responderam não serem frequentes e $36 \%$ serem frequentes. No Gráfico 1 pode-se verificar o nível de frequência dos mesmos à biblioteca. Dos frequentes, 14 disseram frequentar uma vez por semana, um até três vezes por semana e um não respondeu.

\footnotetext{
${ }^{5}$ Da esquerda para direita: professor de História da turma, bibliotecária do colégio (ao fundo alunos da disciplina Organização de Bibliotecas Escolares), professora da disciplina Organização de Bibliotecas Escolares, aluno de Biblioteconomia e Documentação da UFS.
} 
Gráfico 1 - Nível de frequência.

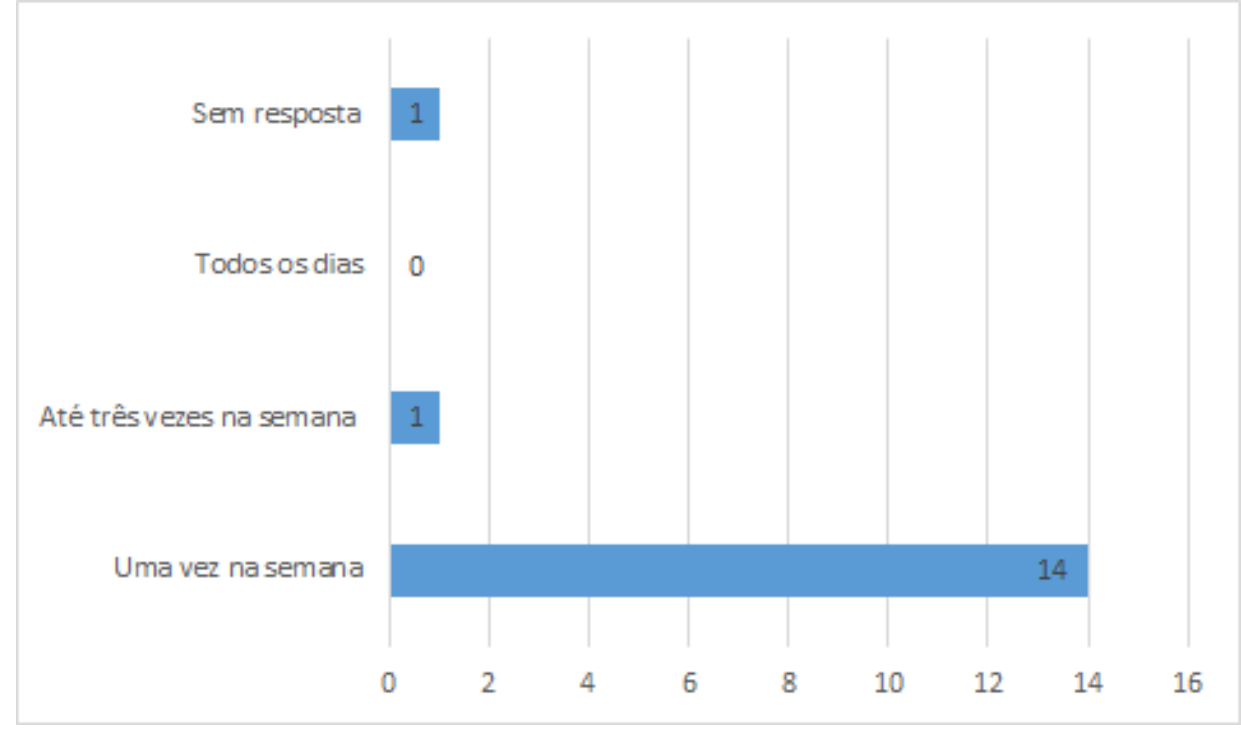

Fonte: dados da pesquisa, 2018.

Este gráfico ilustra a situação da frequência dos alunos à biblioteca, todos vivenciando o processo intensivo para o vestibular. Sabe-se que o preparo para o vestibular é um período intenso de estudos, busca e uso de informações e a biblioteca deveria ser um dos espaços bem frequentados pelos alunos. Dos 36\% frequentes (16 alunos), 14 responderam ir apenas uma vez por semana, de fato o espaço praticamente inexiste para esses alunos do ensino médio vestibulandos.

Percebe-se que o ambiente da biblioteca não atrai de forma efetiva a maior parte dos jovens, apesar de ser agradável, climatizado e de fácil acesso dentro da escola, contando com bibliotecária. A biblioteca Marcos Pinheiro Monteiro funciona de segunda à sexta-feira de 07 às 12:00 hs e das 14:00 às 17:00 hs, possui microcomputadores, acervo catalogado e informatizado em sistema próprio, mesas de estudo coletivo e cabines individuais.

No questionário perguntou-se, ainda, se os jovens já haviam participado de algum projeto promovido pela biblioteca, $47 \%$ disseram já terem participado e $53 \%$ não, como está ilustrado no Gráfico 2.

Gráfico 2 - Participação dos alunos em projetos da biblioteca

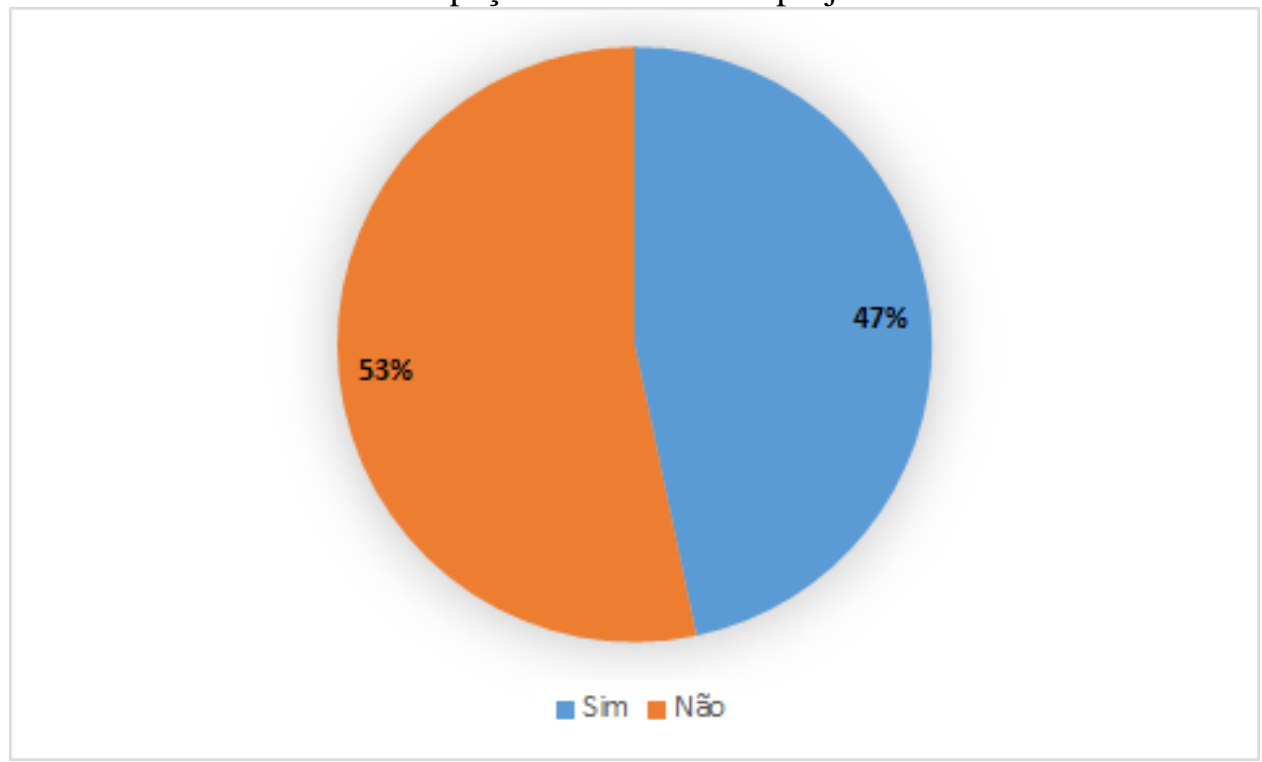

Fonte: dados da pesquisa, 2018. 
Em vista dos dados do Gráfico 2 e em comparação com o Gráfico 1 (frequência), podese observar que mesmo os alunos não frequentando a biblioteca, o trabalho proativo da bibliotecária alcança os alunos em sala de aula, um aspecto positivo de se trabalhar com projetos dentro da escola. As atividades desenvolvidas na biblioteca transpõem as paredes físicas do acervo, reafirmando o papel da biblioteca sem paredes, acessível e que atende as necessidades de sua comunidade (ORTEGA Y GASSET, 2006). No entanto, ressalta-se a importância de se incentivar a frequência dos alunos à biblioteca, já que é durante a educação básica que se forma o usuário de bibliotecas (CAMPELLO, 2003).

A biblioteca possui total apoio pedagógico para atualização do acervo e realiza projetos de extensão, dentre eles pode-se mencionar o projeto Biblioteca Viva, no qual são realizados palestras, oficinas e saraus literários. Outro projeto importante realizado pela biblioteca é o Clube do Livro, voltado para os alunos do $6^{\circ}$ ao $9^{\circ}$ do ensino fundamental; bem como o projeto SOL, que tem como objetivo estimular a solidariedade dos alunos do ensino médio por meio de atividades em instituições sociais. Essas ações realizadas buscam o estímulo à leitura, à cultura e ao uso da biblioteca como local de aprendizado e ação cultural.

Para além do entendimento sobre a frequência e atividades, o questionário também abordou a relação com a informação de modo geral. Assim, perguntou-se quais as formas que o aluno utilizava para obter informação, sendo possível marcar mais de uma alternativa, conforme é possível observar no Gráfico 3:

Gráfico 3 - Métodos adotados pelos alunos para obter informação

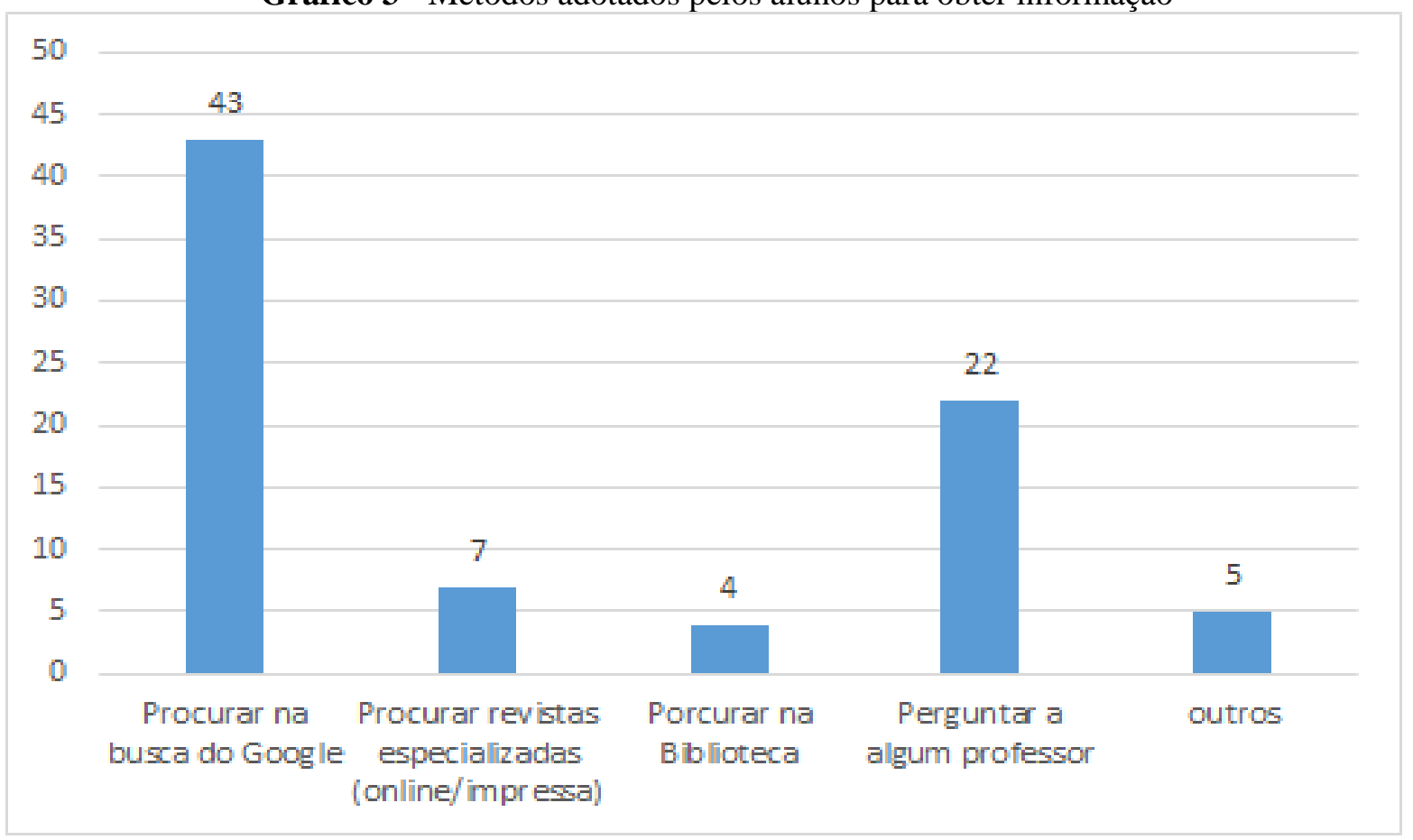

Fonte: dados da pesquisa, 2018.

Dentro da alternativa "outros", cinco alunos responderam da seguinte forma: perguntar a alguém, no google e em mais de uma fonte pra ter certeza, pergunto a algum amigo/familiar, perguntar a terceiros e Twitter. Nota-se que não houve compreensão total desta questão, já que as respostas feitas na alternativa "outros" poderiam ser enquadradas nas demais alternativas pré-selecionadas. A única exceção foi a resposta "Twitter", uma vez que não se enquadra nas pré-selecionadas. Ademais, é notável o baixo número de procura à biblioteca para ter acesso à informação, representando apenas $9 \%$ de todos os alunos consultados. Reflexo, como já demonstrado, da baixa procura pela mesma. 
O Google apareceu com alta demanda, o que corrobora com outros estudos nacionais e estrangeiros de busca de informação por jovens (FIALHO; ANDRADE, 2007). Interessante também observar o papel relevante do professor para orientá-los; nesse sentido, estudos comprovam que professores e bibliotecários devem se unir na escola para trabalhar com os jovens em projetos que proporcionem o avanço do LI dos mesmos.

Já que o meio eletrônico é o preferido dos jovens para buscar informação, o que, de certa forma, já era esperado, perguntou-se também como eles avaliavam a informação na internet, sendo possível marcar mais de uma opção. Tal questionamento gerou o Gráfico 4:

Gráfico 4 - Métodos adotados de avaliação da informação

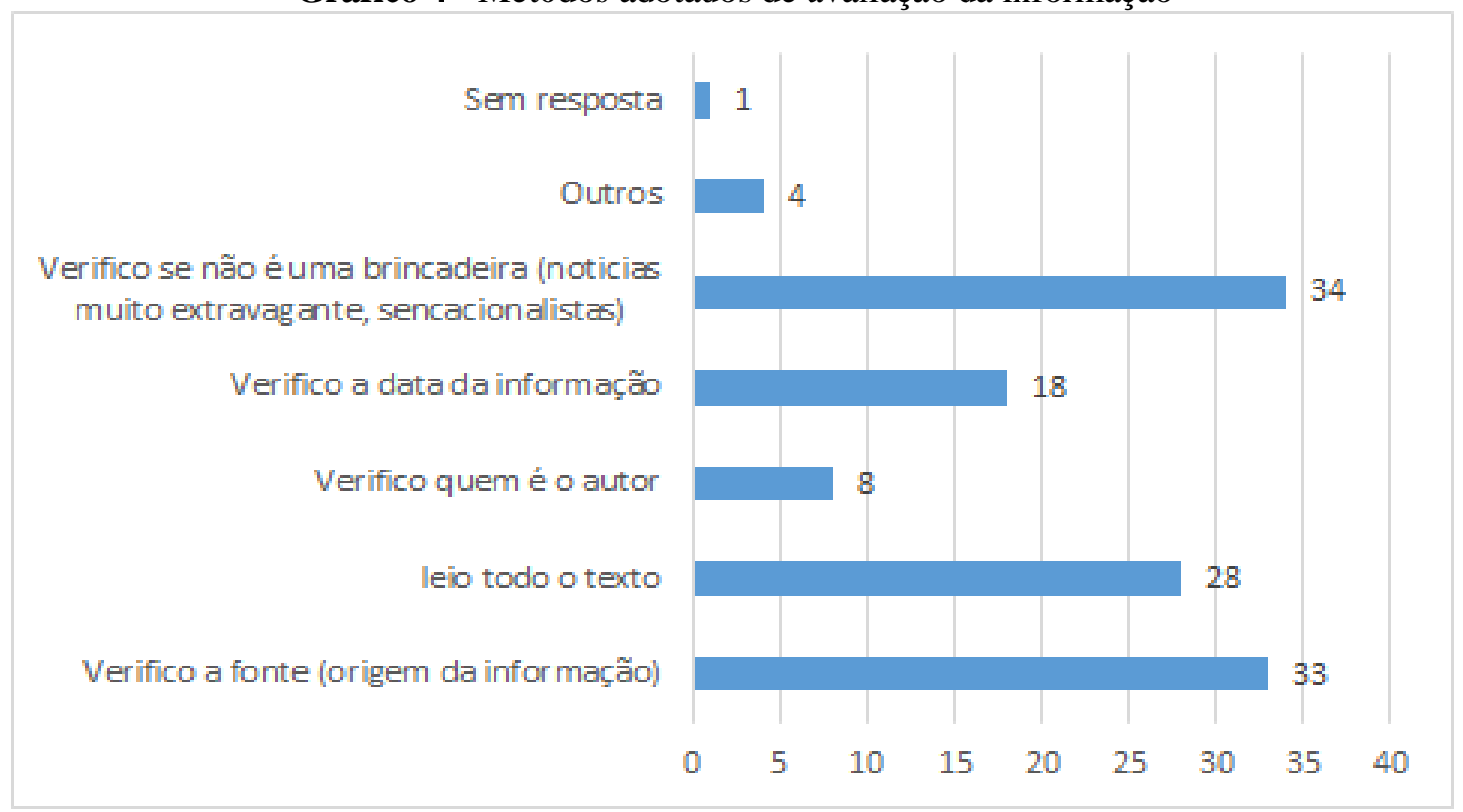

Fonte: dados da pesquisa, 2018.

$\mathrm{Na}$ opção outros surgiram as seguintes respostas: "verifico onde a informação é postada", "pode ser verdadeira se for ao top trendings no Twitter"; "não faço nada" e "leio superficialmente a notícia".

Gráfico 5 - Compartilhamento de notícias falsas

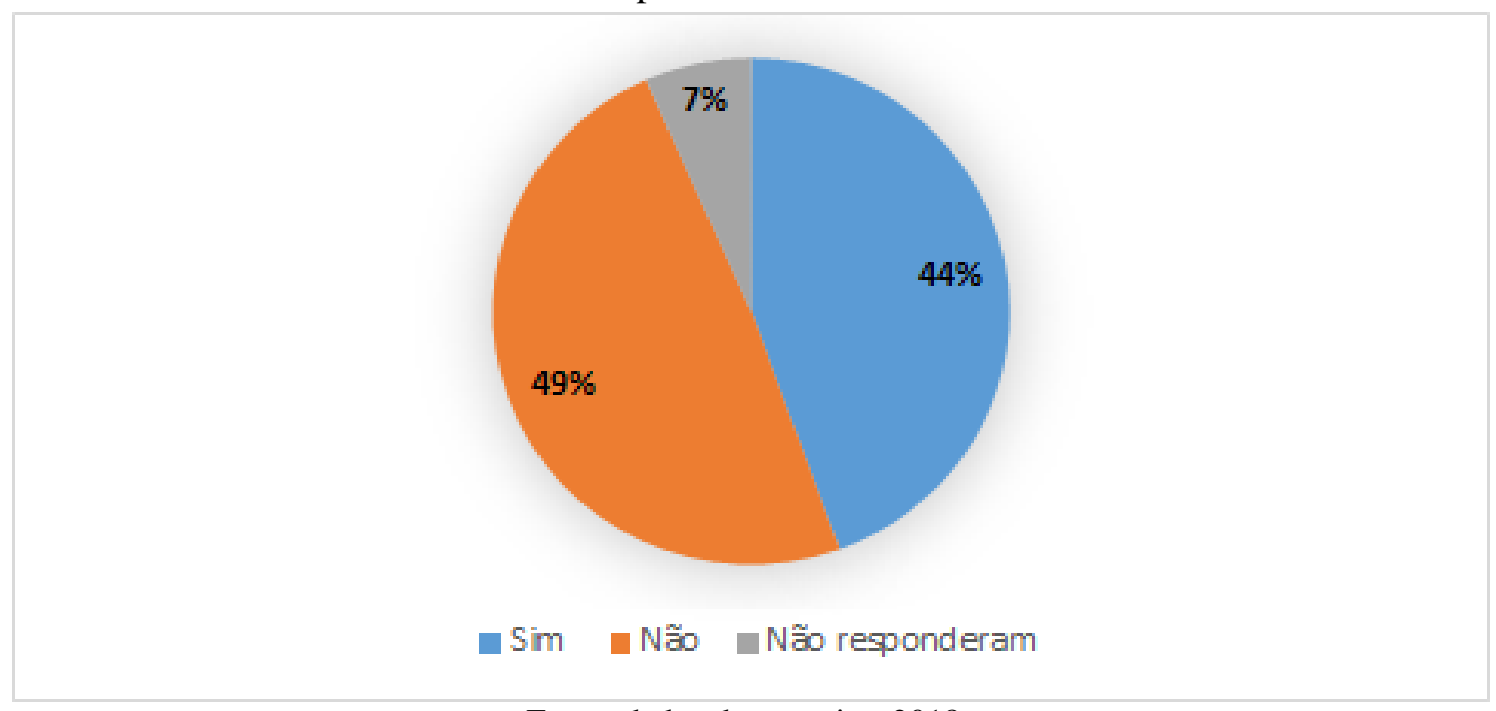

Fonte: dados da pesquisa, 2018. 
Em relação ao compartilhamento de notícias falsas, $44 \%$ responderam que as compartilham, $49 \%$ que não compartilham e $7 \%$ não responderam a questão. Uma pesquisa mais aprofundada seria necessária nesse tópico, pois o grande número de compartilhamentos pode estar associado à falta do senso crítico no uso da informação, ou seja, à falta de discernimento. Por fim, uma questão aberta após a palestra intencionou saber as contribuições da palestra para os alunos, representadas no quadro a seguir:

Quadro 1 - Contribuições da palestra

\begin{tabular}{|l|c|c|}
\hline \multicolumn{2}{|c|}{ ESSA PALESTRA CONTRIBUIU PARA } \\
\hline Ampliar conhecimento sobre notícias falsas & 32 & $71,1 \%$ \\
\hline Aprender técnicas para combater as notícias falsas & 29 & $64,4 \%$ \\
\hline Checar a veracidade das informações & 7 & $15,5 \%$ \\
\hline Auxiliar na redação para o vestibular (ENEM) & 7 & $15,5 \%$ \\
\hline Esclarecer Dúvidas & 6 & $13,3 \%$ \\
\hline Compreender a importância da biblioteca escolar & 1 & $2,2 \%$ \\
\hline Compreender a importância do bibliotecário & 3 & $6,6 \%$ \\
\hline Ampliar conhecimentos sobre a Biblioteconomia & 3 & $6,6 \%$ \\
\hline $\begin{array}{l}\text { Despertar a vontade de compartilhar o que } \\
\text { aprendeu }\end{array}$ & 2 & $4,4 \%$ \\
\hline
\end{tabular}

Fonte: dados da pesquisa, 2018.

Ao analisar as respostas, percebe-se que a palestra foi bastante significativa para os alunos, principalmente por ampliar o conhecimento sobre a temática e ajudá-los a combater as notícias falsas. Houve um interesse por parte da escola para que a palestra fosse estendida para outras turmas, tanto do ensino médio quanto do fundamental.

\section{CONSIDERAÇÕES FINAIS}

Este trabalho teve grande significado para os discentes do curso de Biblioteconomia e Documentação da UFS no sentido de conscientizá-los sobre o papel social do bibliotecário e seu dever ético de combater as notícias falsas. Acredita-se que a disciplina, além de ensinar os critérios técnicos para organização das bibliotecas escolares, atingiu seu objetivo na formação crítica do bibliotecário escolar. Tal iniciativa faz parte de um conjunto de medidas que vêm sendo implementadas no sentido do desenvolvimento das metodologias ativas de aprendizagem no curso de Biblioteconomia e Documentação, nas quais os alunos são protagonistas e se envolvem profundamente com os conteúdos.

Importante ressaltar a parceria entre os professores do curso, pois o trabalho teve a colaboração da docente responsável pelo conteúdo de "Mediação da informação". Após essa iniciativa, os alunos têm sido convidados para ministrarem palestras em escolas e faculdades da cidade e realmente se encantaram pela temática. Os objetivos da pesquisa foram alcançados, ou seja, a conscientização dos alunos do ensino médio sobre a temática e da importância da biblioteca neste cenário. No entanto, o trabalho precisa ser continuado e alcançar maior amplitude quantitativa e qualitativa dentro da escola.

Destaca-se, ainda, a importância do conteúdo de LI na formação do bibliotecário para o combate às notícias falsas. Apesar desse tema ter ganhado contorno e relevância recentemente, 
a biblioteconomia escolar americana vêm se dedicando ao LI desde a década de 1960. No âmbito escolar, o bibliotecário e o professor são profissionais extremamente importantes para a formação de pessoas críticas com o uso da informação, e tal aprendizado serve também para outras esferas da vida, mas a escola deve fornecer a base, daí a importância do desenvolvimento de metodologias por toda a educação básica. Na escola pesquisada, percebe-se que a bibliotecária tem postura ativa e desenvolve projetos literários, sugere-se que a mesma desenvolva projetos em parceria com professores voltados à prática da pesquisa e ao desenvolvimento do LI.

Nesse sentido, Portugal tem desenvolvido e avaliado seu programa de bibliotecas escolares com bastante êxito. No Brasil, trava-se uma batalha muito grande para que as escolas tenham bibliotecas bem estruturadas e profissionais bibliotecários, a exemplo da lei 12.244/10. Espera-se que outras iniciativas no curso venham se somar a essas e que o profissional bibliotecário saia cada vez mais a campo, numa profunda conexão com as demandas sociais.

\section{REFERÊNCIAS}

AQUINO, Mirian de Albuquerque. A ciência da informação: novos rumos sociais para um pensar reconstrutivo no mundo contemporâneo. Ci. Inf. , Brasília, v. 36, n. 3, set./dez. 2007. Disponível em: < http://www.scielo.br/pdf/ci/v36n3/v36n3a02.pdf>. Acesso em: 08 Mar 2018.

CAMPELLO, Bernadete Santos. O movimento da competência informacional: uma perspectiva para o letramento informacional. Ci. Inf., Brasília, v. 32, n.3, p. 28-37, set./dez. 2003. Disponível em: <http://www.scielo.br/pdf/ci/v32n3/19021.pdf >. Acesso em: 01 ago. 2018.

A competência informacional na educação para o século XXI. In: . et al. A biblioteca escolar: temas para uma prática pedagógica. 2. ed. Belo Horizonte: Autêntica, 2016.

.; ABREU, Vera Lúcia Furst Gonçalves. Competência informacional e formação do bibliotecário. Perspectivas em Ciência da Informação, Belo Horizonte, v. 10, n. 2, p. 178193, jul./dez. 2005.

CORRÊA, Elisa Cristina Delfini; CUSTÓDIO, Marcela Gaspar. A informação enfurecida e a missão do bibliotecário em tempos de pós-verdade: uma releitura com base em Ortega y Gasset. Revista Brasileira de Biblioteconomia e Documentação, São Paulo, v. 14, n. 2, p. 197-214, maio 2018.Disponível em: 〈https://rbbd.febab.org.br/rbbd/article/view/777/1043>. Acesso em: 11 maio 2018.

FIALHO, Janaina; ANDRADE, Maria Eugênia Albino. Comportamento informacional de crianças e adolescentes: uma revisão da literatura estrangeira. Ci. Inf., Brasília, v. 36, n.1, p. 20-34, jan./abr. 2007. Disponível em: 〈http://www.scielo.br/pdf/ci/v36n1/a02v36n1 >. Acesso em: 08. ago. 2018.

.; GASQUE, Kelley Cristine Gonçalves Dias. Letramento informacional no contexto escolar. In: SANTOS, Andréa Pereira dos (Org.). Letramento informacional: aspectos teórico-conceituais. Goiânia: CIAR/UFG, 2014. 
GASQUE, Kelley Cristine Gonçalves Dias. Letramento informacional: pesquisa, reflexão e aprendizagem. Brasília: Ed. FCI/UnB, 2012. 181 p.

GIL, Antonio Carlos. Como elaborar projetos de pesquisa. 3. ed. São Paulo: Atlas, 1991.

HERNÁNDEZ SAMPIERI, Roberto; FERNÁNDEZ COLLADO, Carlos; BAPTISTA

LUCIO, María del Pilar. Metodologia de pesquisa. 5. ed. Porto Alegre: Penso, 2013. 624 p.

KIELY, Eugene; ROBERTSON, Lori. How to spot fake news. Disponível em:

<https://www.factcheck.org/2016/11/how-to-spot-fake-news/>. Acesso em: 28. abr. 2018.

MAROTO, Lucia Helena. Biblioteca escolar, eis a questão! Do espaço do castigo ao centro do fazer educativo. 2. ed. Belo Horizonte: Autêntica Editora, 2012.

MINAYO, Maria Cecília de Souza; SANCHES, Odécio. Quantitativo-Qualitativo: oposição ou complementaridade? In: Caderno de Saúde Pública da Escola Nacional de Saúde Pública da Fiocruz, jul./set., 1993. Disponível em:<http://www.scielo.br/pdf/csp/v9n3/02.pdf>. Acesso em: 31. ago.2018.

ORTEGA Y GASSET, José. Missão do bibliotecário. Brasília: Briquet de Lemos, 2006.

REDE DE BIBLIOTECAS ESCOLARES. Aprender com a biblioteca escolar: Referencial de aprendizagens associadas ao trabalho das bibliotecas escolares na Educação Pré-escolar e no Ensino Básico. Lisboa: RBE, 2017. 130 p. Disponível em: <http://www.rbe.minedu.pt/np4/np4/?newsId=681\&fileName=Aprender_com_a_biblioteca_escolar.pdf $>$. Acesso em: 11. abr. 2018.

TODD, Ross James; KUHLTHAU, Carol C. Student learning through Ohio school libraries, part 1: how effective school libraries help students. School Libraries Worldwide, v. 11, n. 1, p. 63- 88, 2005. 